\title{
IMPLICATIONS OF PENTAGON THEORY OF CONTEXTUALIZED MULTIPLE INTELLIGENCES (CMIs) FOR FUTURE JOB PROSPECTS OF UNIVERSITY STUDENTS
}

\author{
Hina Amin \\ Ph.D. Scholar, \\ Institute of Education \& Research, University of the Punjab, \\ Punjab, Pakistan \\ Email: hina.amin@vu.edu.pk
}

\author{
Abid Hussain Chaudhary \\ Professor, \\ Institute of Education \& Research, University of the Punjab, \\ Punjab, Pakistan \\ Email: dean.education@pu.edu.pk
}

\begin{abstract}
The Purpose of the study was to test the Pentagon theory of Contextualized Multiple Intelligences (CMIs) in the context of fourth industrial revolution. It also explored the awareness of students regarding the trends and challenges of future job market. Lastly, skills and competences required by graduate to meet the complexities of future job market were also investigated. This study followed the critical paradigm, therefore sequential explanatory mixed method research design was used. All the masters' level students, heads of departments/ senior faculty members and experts of social sciences were considered as population for this study. Multistage sampling techniques was employed to select the sample size for quantitative phase $(n=786)$. For qualitative phase, purposive sampling technique was used and 12 experts of social sciences were selected. Self-developed questionnaires were used to collect data from respondents. Contextualized Multiple Intelligences questionnaire has 32 statements under 6 factors with Cronbach's Alpha value of 0.92. Similarly, Future Job Market Prospects questionnaire has 20 statements under 4 factors with Cronbach's Alpha value of 0.91 . Semi-structured Interview protocol was developed and used during the qualitative phase. Study revealed positive and strong correlation between the contextualized multiple intelligences and future job market prospects. However, the public universities students showed relatively larger correlation $(r=.631, p=.000)$ as compared to private universities students $(r=.556, p=.000)$. Furthermore, male and female students have differences in their contextualized multiple intelligences. Besides, students exhibited high level of understanding regarding the need of market driven
\end{abstract}


content and importance of employability skills. Experts (Qualitative data analysis) highlighted the need for active role of universities in re-skilling students with contextualized multiple intelligences to make them more desirable for employability.

\section{KEYWORDS}

Contextualized multiple intelligences, future job market, university students, mixed method research, employability, skills, globalization, $21^{\text {st }}$ century education

\section{INTRODUCTION}

Currently, the educational tools, instructional design, techniques and curriculum that are being used since decades may no longer be fit for the purpose of higher education. According to Penprase (2018), students who will be capable of innovations, creative insights within their context, collaborate diversely in different teams and navigating through multi-cultural environment will have an advantage in a workplace as compared to their fellows. He further explained that the workplace of future will be a place where qualities like interpreting information quickly, utilizing contextual resources, being able to work with experts and stake holders towards common understanding and benefits of sustainable development will be essential elements of every job.

Cheng \& Townsend (2000) explained that tremendous impact of technologies and its impact on work, recruitment and future job markets have driven the need of numerous educational and social developments globally. Kurzweill (2005) foresee a future in which the pace of technological changes will be huge and rapid but its impact will be so deep that human life will be irreversibly transformed on every aspect i.e. political, cultural, social and technological. Schwab (2016) also endorsed that the scale, scope, and complexity of the transformations will be unlike anything humankind has experienced before. Resultantly, humankind will find itself at the beginning of a new revolution i.e. Fourth Industrial Revolution $\left(4^{\text {th }} \mathrm{IR}\right)$. Brynjolfsson $\&$ McAfee (2014) further stated that the technological progress could leave many people even countries behind, because computers, artificial intelligence and other digital technologies are acquiring ordinary (soft) skills and abilities at an extraordinary rate. Questions to prepare young and current generations for forthcoming challenges of knowledge economy are now of major concerns (business) for every organization. It's evident from numerous findings that successful functioning of all other levels of an education system is largely depends on the higher education institutions and its performance in a country (NEP, 2107).

Catalytic role of higher education is not limited to nurturing potentials of individual students for their career growth but it's also provides highly skilled human resources needed for economic development, social transformation, and political enlightenment 
of whole society (NEP, 2107). Thus, in this context, Employers' Perception Survey (2018) was conducted to evaluate the skills gap in Pakistani graduates and findings revealed that $78 \%$ Pakistani employers are dissatisfied with the skills and competencies possesses by university graduates. Another study reported by Saeed (2015) to identify competencies gaps between graduates' skills and employer's requirement; he found significant gaps in both technical and non-technical skills. Likewise, another study reported by Jabeen (2011) by comparing the students' perceptions and employers' expectation, she found a mismatch regarding skills that qualify students to be employed and desired by organizations.

Furthermore, Raza and Naqvi (2011) reported that employers are dissatisfied with quality of Pakistani university graduates in all four types of development skills i.e. social, technical, professional and personal. Only the personal skills were relatively strong, followed by intellectual, professional skills, and social skills were being the weakest. In this context, this research aims find out the relationship of contextualized multiple intelligences (CMIs) and future job market prospects of university students. It also explored the awareness of students regarding the trends and challenges of future job market in the context of fourth industrial revolution. Lastly, skills and competences required by graduates to meet the complexities of future job market were also explored.

\section{LITERATURE REVIEW}

Since the last decade, enormous challenges and opportunities have ascended in education in the context of globalization, transformation and fast paced development of information technology (Cheng, 2000). He emphasized the inevitability of paradigm shift in education and calls for reforms to meet the unforeseen challenges within local and international communities in $21^{\text {st }}$ century (Mauch \& Sabloff, 1995; Armstrong, Thompson, \& Brown, 1997; Hirsch \& Weber, 1999; Lick, 1999; Mingle, 2000; EURYDICE European Unit, 2000; Kogan \& Hanney, 2000). Cheng (2005) stated that the questions "How education should respond to the trends and challenges of future job market and fourth industrial revolution has become a major concern in policy making in these years" (p.73). Similarly, increasing demands of skillful individuals within local communities to collaborate at global level in new era, not only globalization but also localization and individualization have become essential elements of educational reforms (ibid.). Browne (2010) asserted that employment of graduates is usually discussed within the context of "knowledge economy" at global, national and local level. They further explained that only concern of tertiary education must be to enhance the full potential -of their graduates for employment regardless of their background. Furthermore, We reiterate that developing employability skills for graduates is an issue for the higher education sector, not only in relation to the first job students may gain after their studies, but also important for graduate prospects at future points of career development or change(p.7) as cited by Pegg et al., (2012). 
Thus, in this context graduating students must be aware of the challenges they would face in near future regarding employment and in their career growth.

\section{Origin of Contextual Intelligence}

Contextual intelligence has its root in psychology in the Triarchic theory of Human Intelligence proposed by Sternberg (1985). He presented an alternate theory against the two theories of same time period; g-factor (single-factor) intelligence and famous multiple intelligence (MI) theory of Gardner (1983). He emphasized that intelligence is not fixed but a set of abilities that can be developed overtime. Individuals demonstrate the abilities to set goals, adapt to, shape and select from the environment using analytic, creative and practical abilities (Sternberg, 2005, p.189). Based on Sternberg's (1985) work, the theory presents contextual intelligence as 'the ability to maximize the contextual elements to influence anybody, in any place, at any time' (Kutz, 2015, p. 11). Although, unlike Gardner theory which only focuses on the personal abilities and intelligences of an individual, Sternberg theory brought the context at the center position in his theory. Explaining the context, Leithwood (2017) distinguished between person -specific context and widely-shared context. The personspecific context explained the personal factors like knowledge, skills, socio-economic condition, literacy levels, experiences, expectations, cultural background, and attitude of a person for a job or at a place. These are the factors which play important role for students or individuals and facilitate them to respond to a problem, process information and react in in a specific situation. These factors influence the individual ability to cope in a certain way and helped him/her to interpret situations. Widely-shared context is the broader concept covering the organizational setting, policies and the role of individual in community and at district level.

The complexities and differences of the contexts vary with respect to different factors and their interaction between them as the context of one place cannot be transferred, imported or exported. External socio-economic and cultural factors may affect the community engagement for one individual in an organization differently (Marishane, 2020). It is a widely accepted fact that highly intelligent individuals easily adjust themselves in a new environment than a less intelligent person (Bray \& Kehle, 2011), because they can use their abilities of adaption, creativity along with contextual factors and better reflect on the situation (Sternberg, 2005). To discuss the connection between contextual intelligence and future jobs prospects, reference is here made to the pentagon theory of contextualized multiple intelligence to better understand the philosophical rationale behind it. The theory is based on the assumption of future of the world, the individual and societal development, aims of education for students and learning, teaching and teachers' pedagogy and the whole for a new paradigm shift (Cheng, 2000). 


\section{Pentagon theory of Contextualized Multiple Intelligences (CMIs)}

According to Cheng (2000), to develop a new generation of workforce to lead the community in complicated multi-cultural environment and work conditions, contextualized multiple intelligences must be at the core of tertiary education. Defining the context, Kutz and Bamford-Wade, (2013) explained that it's the relations, interaction and interdependence among and between contextual elements (e.g., ideas, people, cultures, values, experiences, etc.), political associations, religious organizations and social contexts. Hence, contextual intelligence refers to the awareness of these interactions between elements that fundamentally inform behaviors in a socially complex multi-cultural environment. Kamal (2017) was of the view that shortcomings of education system and emerging technology will lead to unemployment, social and political chaos. Graduates of future will change 5-7 jobs on average in their life time. Thus, it's the responsibility of policy makers to put more focus on up-skilling and re-skilling of graduates and make them able to synthesize information within local and global context. Cheng (2000) stated that intelligence can be contextualized and categorized into the following six Contextualized Multiple Intelligences (CMI) named as Pentagon Theory. It includes the Economic intelligence; Technological intelligence, Social intelligence; Political intelligence; Cultural intelligence and Learning intelligence. The following figure shows the pentagon theory of CMIs.

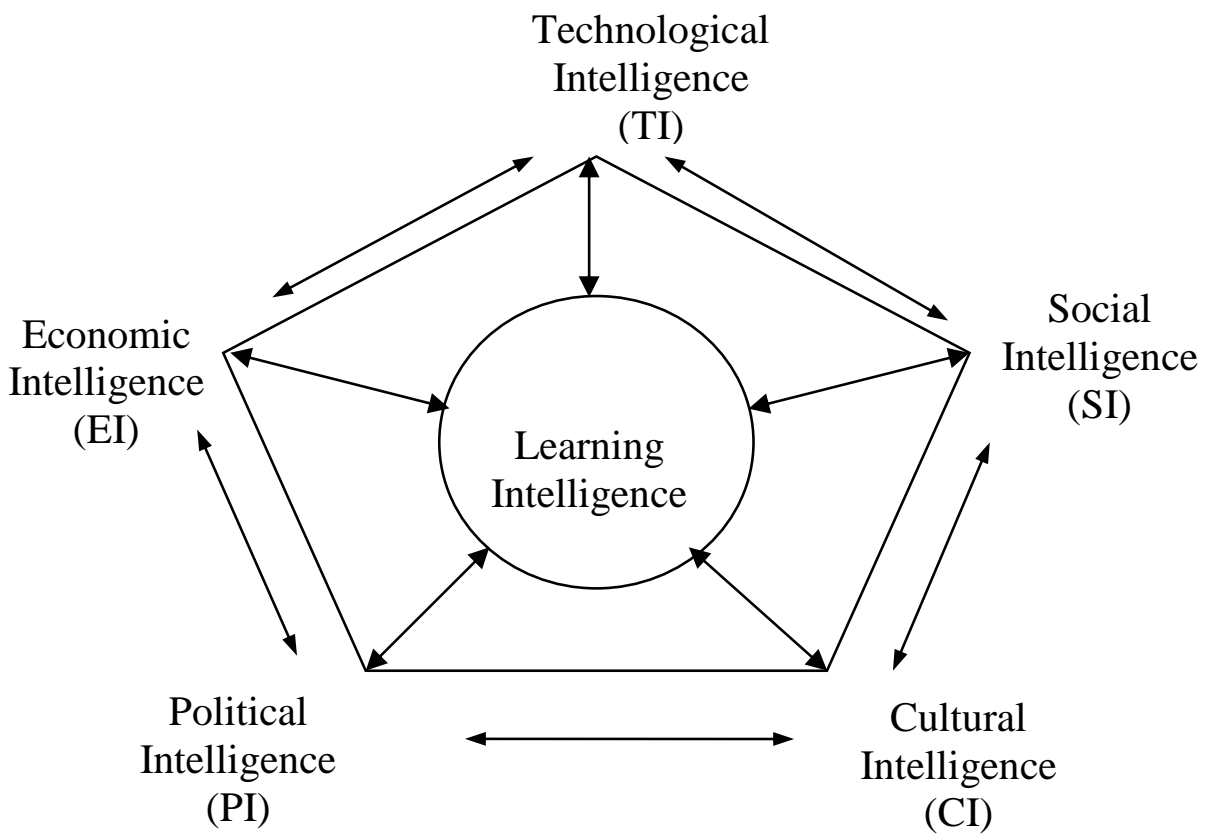

Figure 1. Pentagon theory (Cheng, 2000) 
Future Job Market Prospects in the Era of Fourth Industrial Revolution World Economic forum has labelled this age as fourth industrial revolution (4IR) (Schwab, 2016). He further highlighted two main concerns which is hindering the implications of the fourth industrial revolution $\left(4^{\text {th }} \mathrm{IR}\right)$ to be efficiently, cohesively and effectively realized by academia and civil society (p. 13). First, he argued that the required level of understanding and leadership across all levels and systems is pretty low to rethink educational, social, economic, and technological developments in the fourth industrial revolution. As a result, at both levels i.e. national and international, the institutional framework to govern the innovations and manage the disruptions is absent altogether (p. 13). Secondly, he highlighted that our world lacks a reliable, positive and shared narrative that outlines the all challenges and opportunities of the fourth industrial revolution. Besides, he is convinced that common narrative is crucial if we want to empower a diverse set of individuals and communities to avoid reaction against the vital changes underway (ibid, p. 13). The exact impact of fourth industrial revolution is still unknown but certainly; it has already become widespread enough to create massive societal implication (Penprase, 2018). For workers or graduates to be desired by employees and competitive, they need to be equipped with the skills to deal the fast-changing environmental and cultural context or circumstances (Brookshire et al., 2007; Barta, 2010; Lin et al., 2012).

They further argued that recent graduates in particular are not qualified enough to meet the demands of future job market hence it leads to the shortage of skillful employees in job market. Moreover, there are several studies available which discussed the skills and competencies required by graduates to be successfully employed and help graduates to prepare for future job market (Barrie, 2004; Breivik, 2005; Callanan and Benzing, 2004; Jane and Higson, 2008; Gault et al., 2010; Finch et al., 2013; Laker and Powell, 2011). Rather, to be desirable in job market, new graduates who do not have relevant work experience have to increase their skills and abilities as per the demands of market. It is their responsibility to develop their competences and work on their technical, personal and social skills. Nowadays, it's important to understand the future job market and equip one -selves with easily available resources online (LópezBassols, 2002). But, this certainly cannot deny that academia is much more responsible for training and educating training students to be ready for job market (Raymond et al., 1993; Brennan et al., 2004 ).

Single dimension intelligence and unfitting skills has demanded education system to reshape higher education particular in these three key areas: to re-connect education and employment; to improve forecast and disruptions in education and policies regarding job market trends and challenges (Lodder, 2016). Therefore, it is inevitable to reconsider the change in the curriculum and instructions within higher education to enable students to comprehend updated knowledge and practice right skills needed to 
excel in fluctuating technological, social, cultural, political and economic scenarios (Penprase, 2018). Likewise, developing critical thinking, creativity and innovation in graduates is an important challenge and required continuous restructurings of existing educational aims, systems and practices.

\section{Theoretical framework}

This study followed the following theoretical explanation for each variable of the pentagon theory of CMIs.

Table 1: Contextualized Multiple Intelligence and Expected Outcomes of Higher Education

\begin{tabular}{|c|c|}
\hline $\begin{array}{c}\text { Contextualized } \\
\text { Multiple } \\
\text { Intelligence } \\
\end{array}$ & Definition of the Contextualized Multiple Intelligence \\
\hline $\begin{array}{l}\text { Technological } \\
\text { Intelligence }\end{array}$ & $\begin{array}{l}\text { It refers to the ability to think, act and manage technologically } \\
\text { and maximize the benefits of various types of technology }\end{array}$ \\
\hline $\begin{array}{l}\text { Economic } \\
\text { Intelligence } \\
\text { Social } \\
\text { Intelligence }\end{array}$ & $\begin{array}{l}\text { It refers to the ability to think, act and manage economically and } \\
\text { to optimize the use of various resources } \\
\text { It refers to the ability to think, act and manage socially and to } \\
\text { effectively develop harmonious interpersonal relationship }\end{array}$ \\
\hline $\begin{array}{l}\text { Political } \\
\text { Intelligence }\end{array}$ & $\begin{array}{l}\text { It refers to the ability to think, act and manage politically and to } \\
\text { enhance win-win outcomes in situations of competing resources } \\
\text { and interests }\end{array}$ \\
\hline $\begin{array}{l}\text { Cultural } \\
\text { Intelligence } \\
\text { Learning } \\
\text { Intelligence } \\
\text { Contextualized } \\
\text { Multiple } \\
\text { Intelligences }\end{array}$ & $\begin{array}{l}\text { It refers to the ability to think, act, and manage culturally, to } \\
\text { optimize the use of multi-cultural assets and to create new values } \\
\text { It refers to the ability to learn and think creatively and critically } \\
\text { and to optimize the use of biological/ physiological abilities. } \\
\text { It refers to the comprehensive ability including technological, } \\
\text { economic, social, political, cultural and learning intelligences as } \\
\text { well as intelligence transfer and creation }\end{array}$ \\
\hline
\end{tabular}
(CMIs)

Source: Cheng (2000)

Conceptual Framework of the Study

The study followed the following conceptual framework as show in Figure 2. 


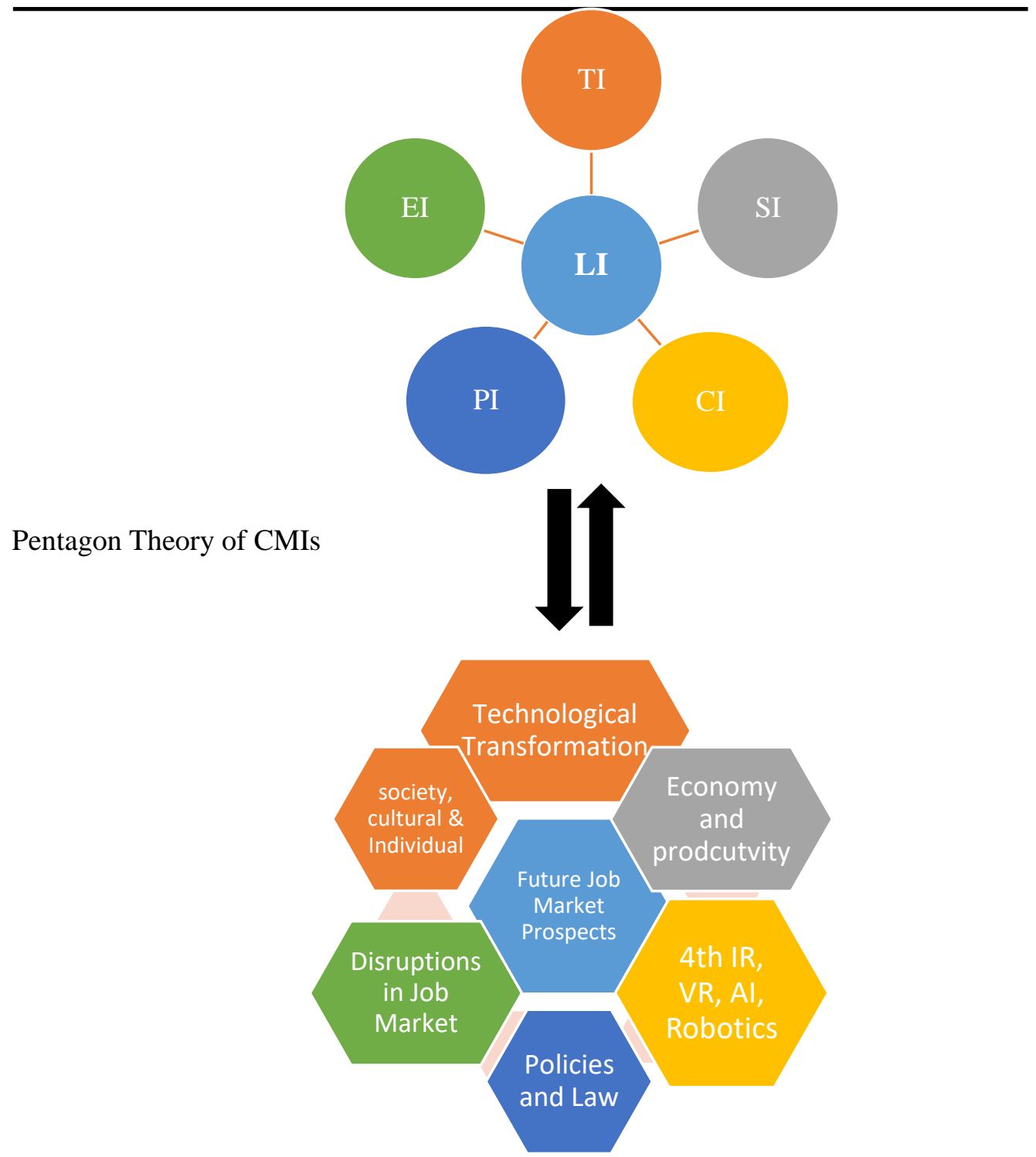

Future Job Market

Fig 2. Conceptual framework of the study

\section{RESEARCH OBJECTIVES}

1. To compare the level of contextualized multiple intelligences in the students of public and private universities; 
2. To compare the awareness regarding future job prospects in the students of public and private universities;

3. To find out the relationship between contextualized multiple intelligences and future job market prospect in the students of public and private universities;

4. To seek the opinions of experts regarding the skills and competencies required by students for future job market;

5. To explore the differences in the contextualized multiple intelligences level and future job market prospects with respect to the demographic variables (gender, sector) among students of public and private universities.

\section{RESEARCH HYPOTHESIS}

1. There is no relationship exists between contextualized multiple intelligences and future job market prospects

\section{RESEARCH METHODOLOGY}

Apropos to the research objectives, the study followed the critical paradigm, therefore sequential explanatory mixed method research design was used. It is evident from the researches that for theory testing, pluralism is the desirable position (De Vaus, 2002; Peters, 2002).

\section{Population and Sample size}

All the students enrolled in the faculty of social sciences in the public and private universities of Punjab was considered as population of the study. By using multi-stage sampling technique, a sample of 786 students (selecting $30 \%$ from public and private strata) were selected for quantitative phase of study. For qualitative phase, 12 experts of faculty of social sciences was selected by using purposive sampling technique. Experts were selected on the bases of following criteria: She/he must have i) five years or more teaching or administrative experience, ii) must be a part of selection board panel iii) willingness to participate in study multiple times as per their convenience.

\section{Instruments}

The researcher used two self-developed questionnaires for quantitative and qualitative phase of study. Questionnaire has two parts, A \& B (contextualized multiple intelligences questionnaire and future job market prospects questionnaire) was based on 5-point Likert scale. For qualitative phase, interview guide was developed after reading relevant literature.

\section{Reliability and Validity of the Instruments}

Validity of the instruments (questionnaires and interview guide) were ensured after seeking review of five educational experts of related filed. Instruments was subjected to content, face, language validity and was finalized after timely feedback from 
experts. After the content, language and structure of the questionnaires were validated, the instrument was piloted tested from $n=98$ students (other than sample) and two faculty members of social sciences department. The reliability for the survey was found as follows:

Table 2: Sub-factors of CMIS scale and Reliability $(n=98)$

\begin{tabular}{cccc}
\hline S. No. & Factor Name & $\begin{array}{c}\text { No. of } \\
\text { Items }\end{array}$ & $\begin{array}{c}\text { Cronbach's } \\
\text { Alpha }\end{array}$ \\
\hline 1 & Economic Intelligence & 6 & .857 \\
2 & Political Intelligence & 7 & .838 \\
3 & Social Intelligence & 6 & .847 \\
4 & Learning Intelligence & 5 & .844 \\
5 & Technological Intelligence & 5 & .841 \\
6 & Cultural Intelligence & 3 & .762 \\
Total & Scale & $\mathbf{3 2}$ & $\mathbf{. 9 2 9}$ \\
\hline
\end{tabular}

Table 3: Reliability of sub-factors of Future Job Prospects (n=98)

\begin{tabular}{|c|c|c|c|}
\hline $\begin{array}{l}\text { Sr. } \\
\text { No. }\end{array}$ & Sub-Factors Name & $\begin{array}{l}\text { No. of } \\
\text { Items }\end{array}$ & $\begin{array}{l}\text { Cronbach's } \\
\text { Alpha }\end{array}$ \\
\hline 1 & F1 Market Based Driven Content & 5 & .898 \\
\hline 2 & $\begin{array}{l}\text { F2 Liaison between University and } \\
\text { Industry }\end{array}$ & 8 & .816 \\
\hline 3 & F3 Scope for Career Growth & 4 & .766 \\
\hline 4 & F4 Importance of Employability Skills & 3 & .748 \\
\hline Total & & 20 & .911 \\
\hline
\end{tabular}

\section{DATA COLLECTION AND ANALYSIS}

First of all, in quantitative phase Google survey was created which also consisted an invitation for students to participate in the study. These faculty members from the selected universities were then requested to share the Google survey link with their students.

Table 4: Response Rate of the study

\begin{tabular}{ccc}
\hline Mode & Frequency & Percent \\
\hline Public & 476 & 77.5 \\
Private & 138 & 22.5 \\
Total & 614 & 100.0 \\
\hline
\end{tabular}

For qualitative phase, two-round Delphi process was used. Delphi process traditionally 
begins with a set of open-ended but un-structured questions (based on quantitative data) named as interview protocol. All the answers were recorded and then transcribed for extracting codes in NVivo. At second round, participants were again contacted to discuss categories emerged from the data in first round. Out of 12, eight respondents participated for round 1 and three for round 2 .

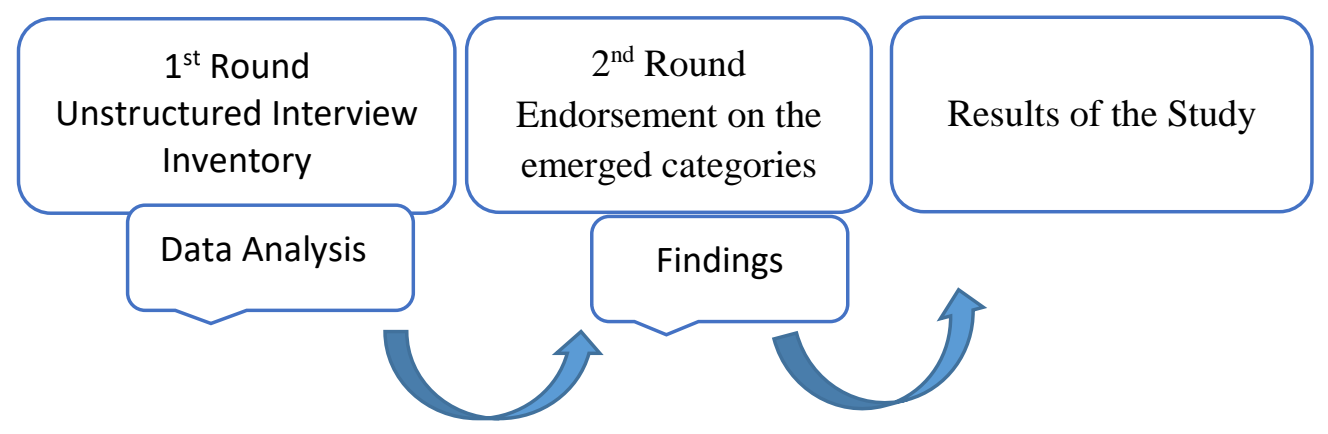

Fig 3. 2-round Delphi

\section{FINDINGS}

After collecting the data, screening and cleaning of data is carried out. To check the normality of the data, descriptive (histogram) and inferential statics (Shapiro-Wilk test) was applied to decide testing based on different variables. For both phase of data collection, ethical concerns were taken into account and discussed prior with the respondents of the study.

i) A Shapiro-Wilk test applied to see the normality of students' data for Contextualized Multiple Intelligences (CMIs). P -value $\alpha=.06$ and normal histogram revealed that responses of students on survey (CMIs) were approximately normally distributed with the skewness of $-.081(\mathrm{SE}=.099)$ and a kurtosis of $-.271(\mathrm{SE}=.197)$ for data. Thus, a parametric statistic could be applied for analysis of data.

ii) When Shapiro-Wilk test was applied to see the normality of students' data for future job market prospects. $\mathrm{P}-$ value $\alpha=.10$ and normal histogram revealed that responses of students on questionnaire Future Job Prospects were approximately normally distributed with the value of skewness is .059 ( $\mathrm{SE}=.099$ ) and kurtosis is -.185 $(\mathrm{SE}=.197)$ for data. Thus, a parametric statistic could be applied for analysis of data. 


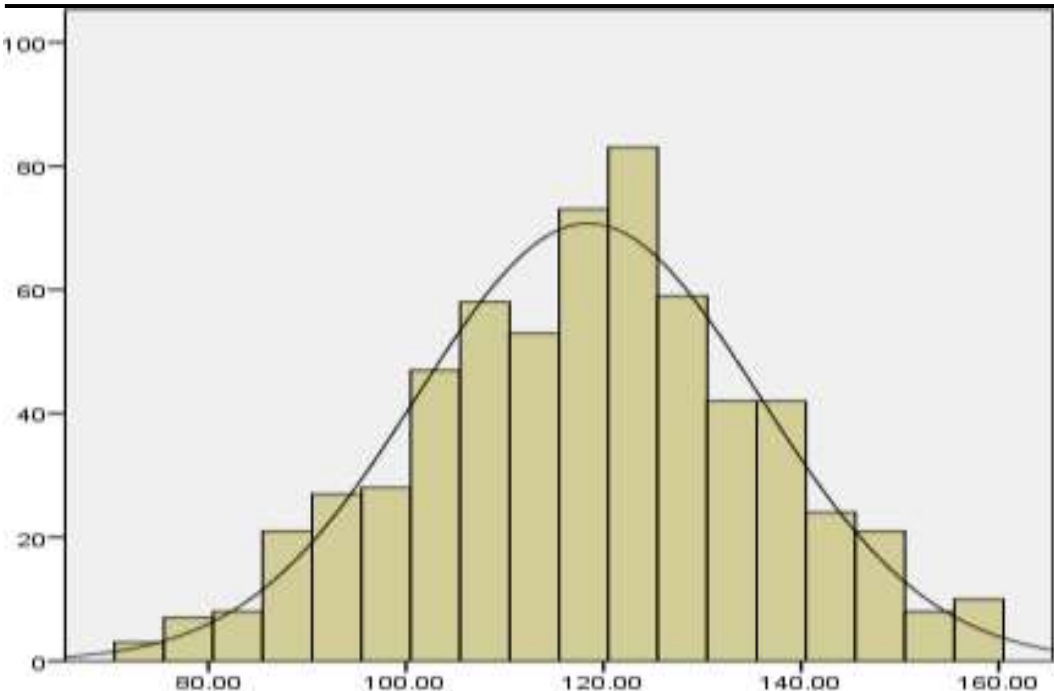

во.о0

100.00

120.00

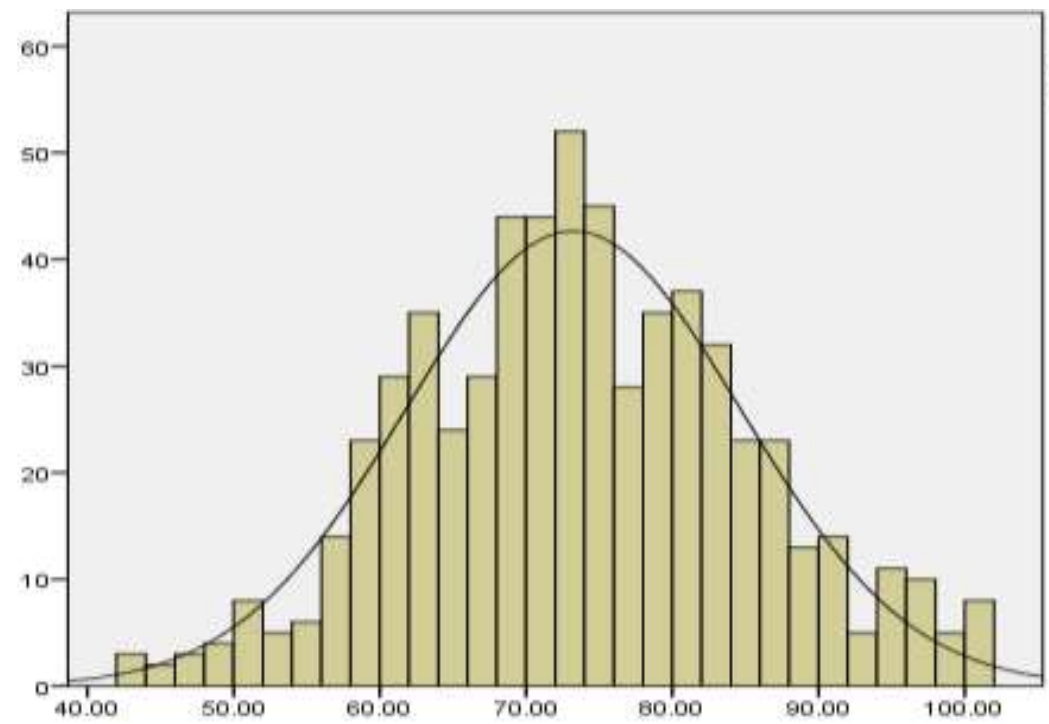

Mean $=73.22$ Stc. Dev $=11,403$

Fig 4, Histograms for CMIs (a) and Future Job Market Prospects (b) questionnaires

\section{Background information}

These figures shows the percentage of respondents' information with respect to gender. Female respondents were almost three time more than their opposite gender. There were 4 age groups for students as data is collected from masters' level students. $80.3 \%$ students belong to group-1 (20-23 years), $15 \%$ belong to group-2 (24-27), only $2 \%$ are from group-3(28-31) and 2.8\% are from group-4 (32 and above). 


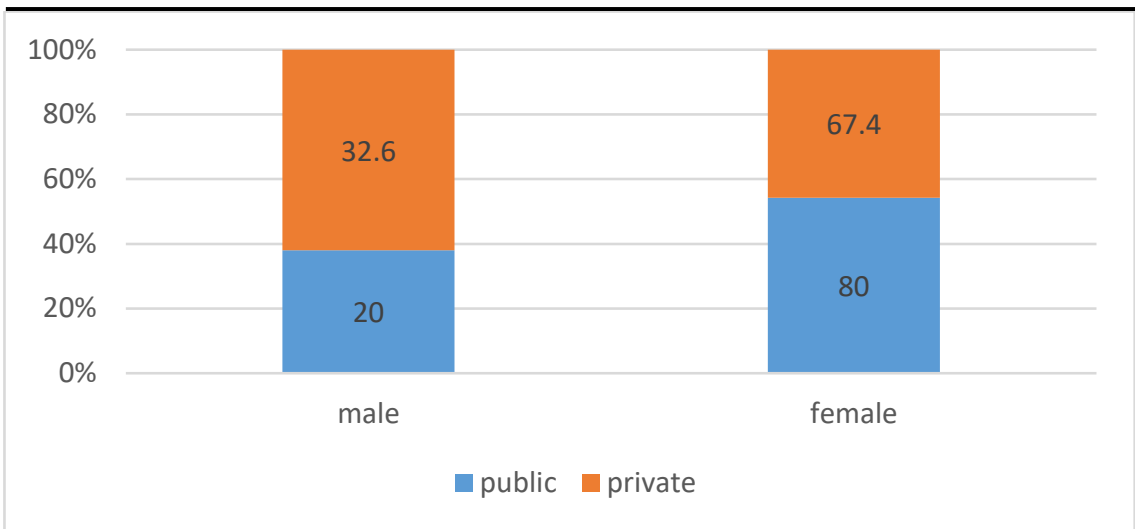

Fig 5. i) Distribution of gender

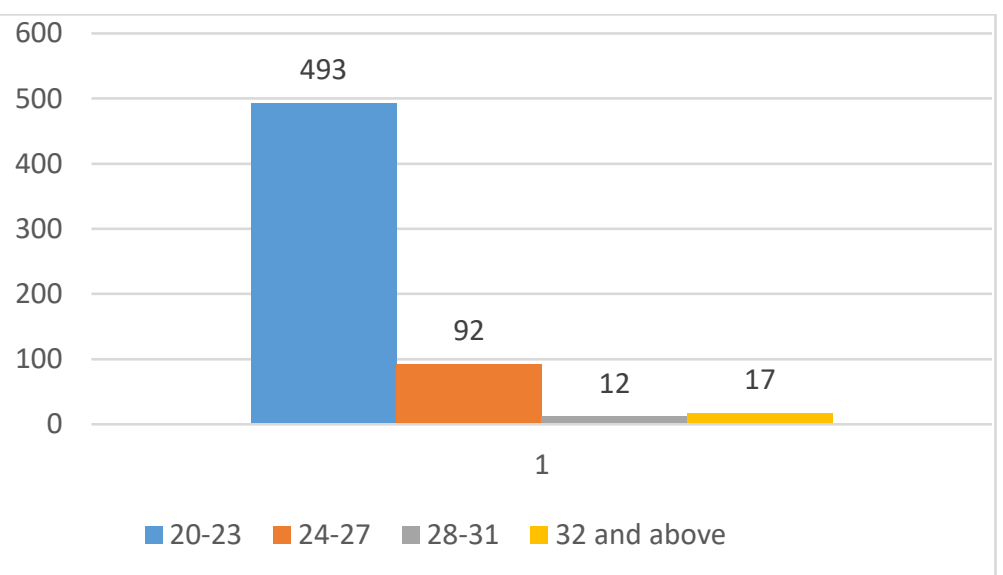

Fig 5. ii) Distribution of age

\section{Descriptive analysis}

To understand the Mean value for each factor, mean value is computed and interpreted according to following criteria (Kaur \& Embi, 2011).

\begin{tabular}{ll}
\hline Perception Degree & Mean Scores \\
\hline High & $3.5-5.0$ \\
Moderate & $2.5-3.4$ \\
Low & $1.0-2.4$ \\
\hline
\end{tabular}

Overall Means of Contextualized Multiple Intelligences (CMIs) and Future Job Market Prospects 
Table 5. Means of CMIs and Future job market prospects $(\mathrm{n}=614)$

\begin{tabular}{llllll}
\hline $\begin{array}{l}\text { Sr. } \\
\text { No }\end{array}$ & Factor Name & & Institution & Mean & Level \\
\hline 1 & Contextualized & Multiple & Public & 3.71 & High \\
& Intelligences & & Private & 3.65 & High \\
2 & Future Job & Market & Public & 3.67 & High \\
& Prospects & & Private & 3.61 & High \\
\hline
\end{tabular}

It has seen that students of public universities are more contextualized multiple intelligent as compared to private university students (Public, M=3.71; Private,

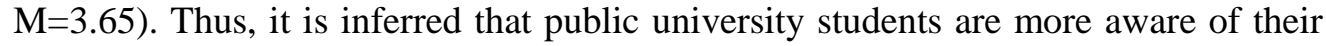
context and may be utilizing the contextual information in their daily practices for academic purposes. Similarly, It is evident that students of public universities are more aware of future job market needs as compared to private university students (Public, $\mathrm{M}=3.67$, Private, $\mathrm{M}=3.61$ ).

After that, factor wise analysis of CMIs and Future job prospects was explored to get a detailed picture.

\section{Sub-factors of CMIs}

Table 6. Means of all sub-factors of Contextualized Multiple Intelligences with respect to Institution (Public $n=476$, Private $n=138$ )

\begin{tabular}{lllll}
\hline $\begin{array}{l}\text { Sr. } \\
\text { No }\end{array}$ & Sub-Factors & Institution & Mean & $\begin{array}{l}\text { Intelligence } \\
\text { Level }\end{array}$ \\
\hline 1 & Cultural Intelligence & Public & 3.63 & High \\
& & Private & 3.60 & High \\
2 & \multirow{2}{*}{ Technological Intelligence } & Public & 3.86 & High \\
& & Private & 3.72 & High \\
\multirow{2}{*}{3} & \multirow{2}{*}{ Political Intelligence } & Public & 3.52 & High \\
\multirow{2}{*}{4} & \multirow{2}{*}{ Economic Intelligence } & Private & 3.45 & Moderate \\
\multirow{2}{*}{5} & \multirow{2}{*}{ Social Intelligence } & Public & 3.86 & High \\
& & Private & 3.71 & High \\
6 & \multirow{2}{*}{ Learning Intelligence } & Public & 3.86 & High \\
& & Private & 3.87 & High \\
& & Privlic & 3.82 & High \\
\hline
\end{tabular}

Above table indicated that overall students of public universities have slightly higher Technological (Public, $\mathrm{M}=3.86$; Private, $\mathrm{M}=3.72$ ), Economic (Public, $\mathrm{M}=3.86$; 
Private, $\mathrm{M}=3.71$ ), and Learning (Public, $\mathrm{M}=3.82$; Private, $\mathrm{M}=3.70$ ) intelligence as compared to private university students. However, for social intelligence, private university students have a little high value of mean (Public, $\mathrm{M}=3.86$; Private, $\mathrm{M}=3.87$ ) thus depicting that private universities students tends to be more social and use this intelligence in their circumstances. Similarly, there is somewhat slight difference in the cultural intelligences for public and private universities students as mean value is (Public, $\mathrm{M}=3.63$; Private, $\mathrm{M}=3.60$ ). Besides, political intelligences of private university students is at moderate level as compared to public universities students (Public, $\mathrm{M}=3.52$; Private, $\mathrm{M}=3.45$ ).

\section{Sub-factors of Future Job Market Prospects}

Table 7. Means of all sub-factors of Future Job Market Prospects with respect to Institution (Public $n=476$, Private $n=138$ )

Below table indicated the overall mean values for all the sub-factors of the future market prospects. Responses indicated that students of public and private universities both have higher perception regarding market driven content (Public, $M=3.85$, Private, $\mathrm{M}=3.85$ ) and importance of employability skills (Public, $\mathrm{M}=3.93$, Private, $\mathrm{M}=3.90$ ). Student of private universities are more slightly aware of the importance of Liaison between university and industry as compared to public university students (Public, $M=3.51$, Private, $M=3.55)$. For scope of career growth, students are at moderate level means they do not foresee the scope of their career growth (Public, M=3.34, Private, $\mathrm{M}=3.32$ ).

\begin{tabular}{|c|c|c|c|c|}
\hline $\begin{array}{l}\text { Sr. } \\
\text { No }\end{array}$ & Factors Name & Institution & Mean & $\begin{array}{l}\text { Perception } \\
\text { Level }\end{array}$ \\
\hline \multirow[t]{2}{*}{1} & \multirow{2}{*}{$\begin{array}{l}\text { Market Driven } \\
\text { Content }\end{array}$} & Public & 3.85 & High \\
\hline & & Private & 3.85 & High \\
\hline \multirow[t]{2}{*}{2} & Liaison between & Public & 3.51 & High \\
\hline & $\begin{array}{l}\text { University and } \\
\text { Industry }\end{array}$ & Private & 3.55 & High \\
\hline \multirow[t]{2}{*}{3} & Scope for Career & Public & 3.34 & Moderate \\
\hline & Growth & Private & 3.32 & Moderate \\
\hline \multirow[t]{2}{*}{4} & Importance of & Public & 3.93 & High \\
\hline & Employability Skills & Private & 3.9 & High \\
\hline
\end{tabular}

\section{Hypotheses Testing}

To test both hypotheses, inferential statics were applied. Pearson's' correlation was applied to find out the strength of the relationship between these two variables. To analyze the strength of the relationship Cohen (1988, pp. 79-81) guidelines were used 
as follows: Small/week $(r=.10$ to .29$)$; Medium/moderate $(r=.30$ to .59$)$ and Large/strong ( $r=.60$ to 1.0$)$.

$\mathrm{H} 0_{1=}$ There is no relationship exists between contextualized multiple intelligences and future job market prospects

Table 8. Correlation between contextualized multiple intelligences and future job market prospects $(n=614)$

\begin{tabular}{cccc}
\hline Variable & Mean & r & Sig. \\
\hline $\begin{array}{c}\text { Contextualized Multiple } \\
\text { Intelligences }\end{array}$ & 3.70 & $.615^{* *}$ & 000 \\
Future Job Market Needs & 3.66 & & \\
$* * \mathrm{p}<.005$ (2-tailed) & & &
\end{tabular}

It is noted that a positive and strong correlation exists between these two variables, $\mathrm{r}=$ $.615, \mathrm{n}=614, \mathrm{p}=000$, with $38 \%$ variance (coefficient of determination) confidence intervals at 0.95 (Lower limit $=.56$; upper limit $=.66$ ) thus rejecting the null hypothesis $\mathrm{H} 0_{1}$. This means that high level of CMIs of students will lead them better understanding of $\mathrm{f}$ future job prospects. Contextualized multiple intelligences helps to explain nearly $38 \%$ of the variance in perceptions of students regarding the future job market.

Regression analysis is the next step after finding the significant and strong correlation between the variables. It is used to predict the value of a variable based on the other variable. This is bivariate study; therefore, linear regression has been applied.

Table 9. Regression

\begin{tabular}{cccccc}
\hline Predictor & $\boldsymbol{\beta 1}$ & $\boldsymbol{R}^{2}$ & $\boldsymbol{d} \boldsymbol{f}$ & $\boldsymbol{F}$ & Sig \\
\hline Constant & 24.935 & .378 & 613 & 371.469 & .000 \\
CMIs & .408 & & & & \\
\hline
\end{tabular}

Dependent variable: Future Market Prospects

Table explained that CMIs predict the significant amount of variance in the future market needs $\mathrm{F}(1,612)=371.469, \mathrm{p}=.000, \mathrm{R}^{2}=.38, \mathrm{R}^{2}$ adjusted $=.37$. The regression coefficient $(\mathrm{B}=.41)$ indicated that any change in CMIs may predict the changes in student's perception towards their employability in future market needs.

Lastly, to see the difference of contextualized multiple intelligences (CMIs) and future Job market prospects with respect to gender and sector. Independent sample t-test was applied to analyze the data. 


\begin{tabular}{|c|c|c|c|c|c|c|}
\hline$\overline{\text { CMIs }}$ & $\mathbf{N}$ & Mean & $\begin{array}{l}\text { Std. } \\
\text { Deviation }\end{array}$ & df & $\mathbf{t}$ & Sig \\
\hline Male & 140 & 122.52 & 16.36 & 239.67 & 3.290 & .001 \\
\hline Female & 474 & 117.26 & 17.42 & & & \\
\hline Public & 476 & 118.80 & 17.20 & 217.58 & .889 & .37 \\
\hline Private & 138 & 117.28 & 17.20 & & & \\
\hline
\end{tabular}

Above table indicates that for gender, as $p$-value" (.001) is less than $p \leq 0.05$, thus concluded that there is difference of contextualized multiple intelligences for male and female students. It is inferred that male students are more contextualized intelligent as compared to their female students. But for sector, as p-value" (.37) is more than $p \leq$ 0.05 , thus concluded that there is no difference of contextualized multiple intelligences for public and private university students.

Table 11. Difference in Future Job Market Prospects based on Gender and Sector $(\mathbf{n}=614)$

\begin{tabular}{ccccccc}
\hline $\begin{array}{c}\text { Future Job } \\
\text { Market } \\
\text { Prospects }\end{array}$ & N & Mean & $\begin{array}{c}\text { Std. } \\
\text { Deviation }\end{array}$ & df & t & Sig \\
\hline Male & 140 & 67.02 & 10.55 & 219.53 & 1.408 & .16 \\
Female & 474 & 65.60 & 10.09 & & & \\
Public & 476 & 66.02 & 10.31 & 230.335 & .427 & .67 \\
Private & 138 & 65.60 & 9.89 & & & \\
\hline
\end{tabular}

Above table indicates that for gender, as $p$-value" (.16) is more than $p \leq 0.05$, thus concluded that there is no difference of future job prospects for male and female students. Similarly, for sector, as p-value" (.67) is more than $p \leq 0.05$, showing no difference with respect to institution.

\section{Qualitative Data Analysis}

After conducting interviews, data was transcribed and then entered in NVivo for better understanding of expert's views. All eight participants were agreed that future job market is changing (Question.1 see linking tree). To explain the change in future job market, Participant from another university (P3) highlighted the change in skills required by the job market by saying that "previously, educationist was expressing upon the scientific skills. But now along with the scientific skills; ICT skills, Social 
skills are also needed". Similarly, focusing the skills needed in classrooms, one participant (P6) said the" Our demand is that what kind of teaching strategy, or how they implement technology in different classroom and they know assessment criteria in classroom. So different things that we will count".

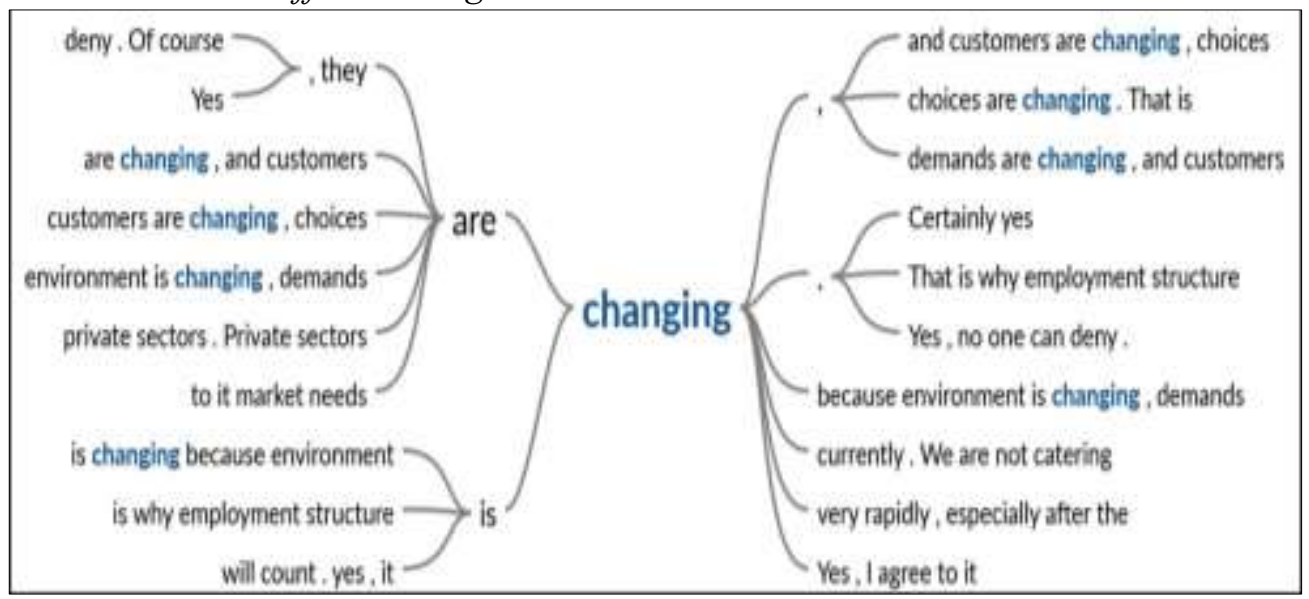

Participants further inquired if they know the buzzing word Fourth Industrial Revolution (4IR) (Question.2) in today's world and how they understand its role for future job market. Six participants out of eight said they know this word and have its understanding. Participant (P3) described term as "In world scenario, power centers are being changed, ICT \& laser technology is on the peak. Nano technology is being introduced in different walks of life. So, I can say that fourth industrial revolution is on way".

Participants were asked to highlight the skills and competencies (Question.3) required by students for their employability in future job market, the following (Hierarchy chart) regarding the skills and competencies were considered important for students. 


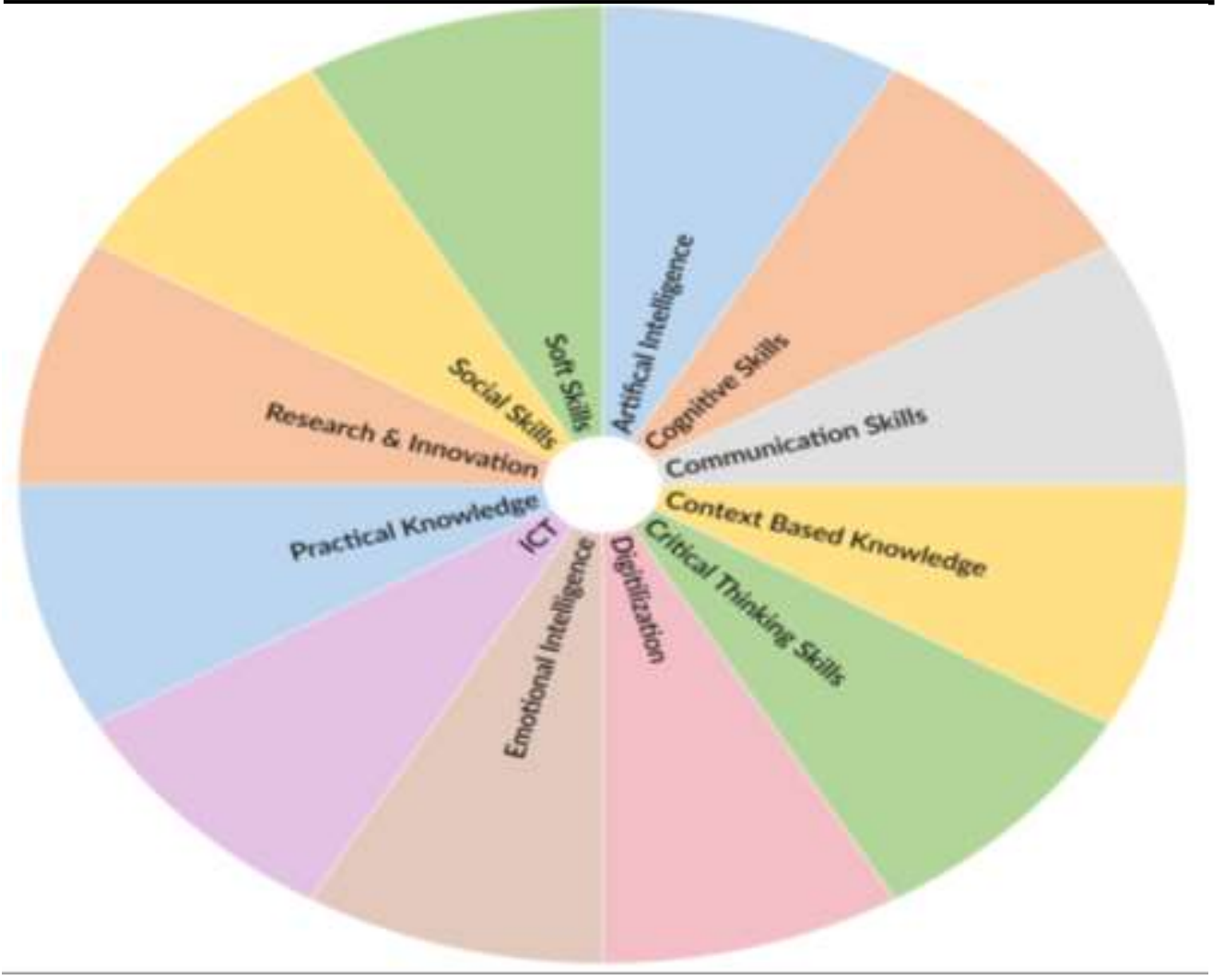

\section{DISCUSSION}

Current study aimed to investigate the level of and of university students. Furthermore, it also explored the relationship between two variables i.e. contextualized multiple intelligences and future job market prospects. When sub-factors of contextualized multiple intelligences of students was compared, it was found that out of all types of intelligences the highest mean is referred to social, learning and economic intelligence for public university students as reported by Mohammadi and Abdsharifi (2014) as well. The reason for the higher level of technological and social intelligences is perhaps the more exposure to the technological and social applications in recent times. During the last whole year, due to lack down and online learning, students were connected with their fellows and teachers through online medium for academic or non-academic purposes. Furthermore, students are using and active on social platforms continuously. This exposure helped them to have higher self-perceived intelligences for social and technological intelligences. When comparison was made for different sub-factors, significant difference of male and female was found for social, cultural, political and cultural intelligence. The findings are aligned with the studies of (Malik et al. 2018) 
and Mohammadi and Abdsharifi (2014) that male students possess higher social intelligence as compared to female students. However, Fellmann and Redolfi (2017) claim that females are dominant than males in social intelligence and related aspects. Contrarily, studies of Ali et al. (2019), Kundu et al. (2015) and Nagra (2014) found no significant differences in the perceptions of male and female students regarding their social intelligence. It is perhaps that both studies are conducted in Indian background and also particularly in Pakistan, females' roles are somehow restricted due to their social and family pressure.

Study also revealed that there is no significant difference regarding prospects of students towards future jobs market needs with respect to gender and sector. However, Saher and Chaudhary (2019) said that in Pakistan, there is strong competition for public and private university graduates for getting jobs (Zafar \& Mat, 2012). It is inferred that as students are product of similar education system and enrolled in universities where syllabus and activities are prescribed by same higher authorities i.e. higher education commission (HEC).

According to Penprase (2018), the exact impact of fourth industrial revolution is still unknown but certainly; it has already become widespread enough to create massive societal implication. Sarkar et al. (2016) reported that identifying skills gaps from graduate perspective might help universities to prepare intervention in curricula to bridge the gap of knowledge and skills. In supporting this argument, Participant P7 responded that in future market "students need to be better equipped with real life job requirements. They need to have more hands-on experience rather than just having theoretical knowledge of concepts". For workers or graduates to be desired by employees and competitive, students need to be equipped with the skills to deal the fast-changing environmental and cultural context or circumstances (Brookshire et al., 2007; Barta, 2010; Lin et al., 2012). Qualitative data also supported the findings of quantitate phase of study as Participant (P1) highlighted the importance of knowledge management in knowledge economy that "knowledge management is very important and perhaps we have to teach our student artificial intelligence, the strategies you have adopt so that the students might click to the right information in minimum time and better perform in their job place".

The study recommended the active role of universities administration to strategize the inclusion of CMIs based content, teaching-learning activities in curricular climate at university level. Universities are expected to take the lead in providing the leadership by incorporating required skills and demands into curriculum and through instructional practices. The collaboration of academia (faculty, students, and researchers), government and industry for research and innovation has demanded universities to device new policies and strategies to involve all stakeholders to produced skilled 
human capital. More effort is required on the behalf of the universities to introduce new and innovative areas for specialization with respect to knowledge and skills. This could be achieved by taking on board the demands of industry and by strengthening university-industry linkage.

\section{REFERENCES}

Ali, A., Ahmad, I., \& Khan, A. (2019). Gender, Age and Locality Based Social Intelligence Differences of B. Ed.(Hons) Students. Global Social Sciences Review, 4(1), 207-213.

Brynjolfsson, E., \& McAfee, A. (2014). The second machine age: Work, progress, and prosperity in a time of brilliant technologies. WW Norton \& Company.

Bray, M. A., \& Kehle, T. J. (2011): The Oxford Handbook of School Psychology. Oxford University Press, Inc

Cheng, Y. C., Chow, K. W., \& Tsui, K. T. (Eds.). (2001). New teacher education for the future: International perspectives. Springer Science \& Business Media.

Cheng, Y.C. (2000). A CMI-Triplization Paradigm for Reforming Education in the New Millennium. International Journal of Educational Management. 14(4), $156-174$

Cheng, Y.C. (2000). A CMI-Triplization Paradigm for Reforming Education in the New Millennium. International Journal of Educational Management. 14(4), 156-174. Or

Cheng, Y. C. (2000). Educational Reforms in the New Century: Multiple Intelligence and Globalization, Localization and Individualization. In the Chinese Educational Research Association (ed.), New Vision of Educational Development in the New Century, (pp. 1-41). Taiwan: Taiwan Books Store. (Chinese)

Cheng, C. Y. (2005). New paradigm for re-engineering education: Globalization, localization and individualization, The Netherlands: Springer. ISBN-10 14020-3620-5 (e-book)

Govt. of Pakistan (2017). National Education Policy. Islamabad: Higher Education Commission

Jabeen, T. (2011). An appraisal of mismatch between graduating Students Perception and Employers' expectation regarding employability skills. Thesis: University of Gujrat, Pakistan

Kutz, M. R. (2015): Contextual intelligence: Smart leadership for a constantly changing world. Perrysburg, Ohio: Roundtable Group.

Leithwood, K., \& Day, C. (Eds.). (2007). Successful school leadership in times of change. Springer.

Leithwood, K. (2017). The Ontario leadership framework: Successful school leadership practices and personal leadership resources. In K. Leithwood, J. Sun, \& K. Pollok (Eds.), How school leaders contribute to student success. 31-43. Springer International Publishing.

Mohammadi, M., \& Abdsharifi, F. (2014). Development and validation of contextualized multiple intelligences based on pentagon theory. Journal of Psychological Models and Methods, 3(14), 67-89.

Marishane, R. N. (2020). Contextual Intelligence in School Leadership: Responding to the Dynamics of Change. Brill 
Marishane, N. R. (2016). Leadership and Context Connectivity: Merging Two Forces for Sustainable School Improvement. Bulgarian Comparative Education Society.

Penprase B.E. (2018). The Fourth Industrial Revolution and Higher Education. In N.W. Gleason (ed.), Higher Education in the era of the fourth industrial revolution (ed.pp.207-229). Palgrave Macmillan, Singapore.

Raza, S., \& Naqvi, S. (2011). Quality of Pakistani University Graduates as perceived by Employers. Implication for Faculty Development. Journal of Quality and Technology Management, 7 (1), 57-72.

Saeed, K. (2015). Gaps in Marketing Competencies between Employers' Requirement and Graduates' Marketing Skills. Pakistan Business Review

Schwab, K.M. (2016, January 14). The Fourth Industrial Revolution: what it means, how to respond. World Economic Forum. Retrieved from https://www.weforum.org/agenda/2016/01/the-fourth-industrial-revolution-whatit-means-and-how-to-respond/

Sarkar, M., Overton, T., Thompson, C., \& Rayner, G. (2016). Graduate employability: Views of recent science graduates and employers. International Journal of Innovation in Science and Mathematics Education, 24(3).

Saher, U. \& Chaudary, H. A., (2019). A Comparison of Self-Perceived Employability of Graduates from Public and Private Universities of Punjab. Bulletin of Education and Research, 41(1), 119-130.

Spearman, C. (1904). "General intelligence", objectively determined and measured. American Journal of Psychology, 15, 201-292.

Sternberg, R. J. (1985). Beyond IQ: A triarchic theory of human intelligence. Cambridge University Press.

Sternberg, R. J. (2005). The theory of successful intelligence. International Journal of Psychology, 39(2), 189-202.

Zafar, J., \& Bint Mat, N. (2012). Protean career attitude, competency development \& career success: A mediating effect of perceived employability. International Journal of Academic Research in Business and Social Sciences, 2(4), 204. 